\title{
Bats Species Diversity of Northern Tajikistan: 45 Years Later
}

\author{
Tolibjon Khabilov*, Dilbar Tadjibaeva \\ Khujand State University named after acad. B. Gafurov, 735700, Khujand, the Republic of Tajikistan
}

\begin{abstract}
The paper shows the results of long-term field studies of the species composition and number of bats in 8 abandoned mines in the Mogol-Tau mountains and the foothills of the northern slope of the Turkestan Mountain ranges in the territory of Northern Tajikistan. It reveals that the species diversity and number of bats have decreased both in "winter" stationary mine in the MogolTau mountains and in "summer" stationary mine in the foothills of the Turkestan Mountain ranges. At the same time, the number of Myotis blythii Tomes 1857 has remarkably increased in summer. The paper suggests that these changes are not directly related to human activities, but have deeper causes and, possibly, are associated with global climate change.
\end{abstract}

So far, bats are one of the most studied groups among mammals in Tajikistan [1-3] due to intensive researches in the second half of the 20th century and their study in the period 2010-2020. However, most of the field work was carried out in the north of Tajikistan and in Zeravshan River valley, and this also had historical reasons. In the $19^{\text {th }}$ century and at the beginning of the $20^{\text {th }}$ century, most Russian zoologists (N.A. Severtsov, A.P. Fedchenko, N.A. Zarudniy) visited this part of the country. Whereas, a small number of zoologist and bats experts made sporadic visits to southwestern Tajikistan, Badakhshan and Pamirs. Therefore, the species composition and distribution of bats in Northern Tajikistan and the Zeravshan river valley, are studied and known to some extent. As for south-western Tajikistan, Badakhshan and Pamirs, the mentioned group are studied in a lesser degree of probability. Hence, it is supposed that even the first ecological-faunistic stage of studies have not yet been carried out to be the basis for all further studies in these areas.

In terms of bats studies, it should also be taken into consideration that along with just methodological difficulties, the mountainous area of Tajikistan i.e. $93 \%$ of the country reaching $5000 \mathrm{~m}$ above sea level, and in the Pamirs exceeding $6000 \mathrm{~m}$ above sea level, creates a number of other difficulties. The mountain factor is, therefore, the most important ecological factor (not counting the anthropogenic one), influencing both on the species diversity of bats as well as on their distribution and number in altitudinal belts, specific to all mountainous countries.

The species diversity of bats in a particular region, in addition to its location, natural and geographic conditions, often depends on the history of its study, from which the most important consequences and conclusions about the fauna and species diversity of the country are drawn. If we look at the history of study of bats in Tajikistan from this point of view, it should be noted that the first scholar to have studied bats of this region was the outstanding Russian zoologist N.A. Severtsov distinguishing 7 species of bats [4]. Even since then, this scholar mentioned about Pipistrellus pipistrellus Schreber, 1774, as a very common sedentary species. And two other species, Otonycteris leucophaea Severtsov, 1873 and Eptesicus gobiensis Bobrinskiy, 1926 found by them, respectively, in Qurama (JanBulak) and Gissar (Lake Iskanderkul) mountain ranges, are still the only finds from this period.

We are not going to detail the works of other scholars dealing with the study of bats, since most of them generally speak about bats along with and connected with the study of other groups of vertebrates of Tajikistan, and that the topic was covered in detail in my early papers [1].

However, in the second half of the twentieth century, O.P. Bogdanov, a wide-profile zoologist and one of the best experts on the fauna of Central Asia and an expert on bats, more thoroughly studied the bats fauna of Tajikistan and supplement it with new information on the species composition, wintering periods, and ecology of bats [5-9].

He summarized all the available data for this period on bats in Tajikistan indicating 16 species of bats of this territory [9]. Although O.P. Bogdanov made the greatest contribution to the study of the species diversity of bats in Tajikistan, nevertheless, he himself was aware that the group was very poorly studied, only the species composition was established more or less fully, and all other aspects of biology and distribution were almost unknown.

In the late 1970s, T.K. Khabilov [1,2, 10-17], undertook a study of the fauna and biology of bats, which resulted in the identification of 19 bat species, data on their distribution, abundance and biology in Tajikistan (Table 1) and the Zeravshan River Valley. The data given in Table 1 is of certain interest, as bats joint studies has been continued since 2009 by T.K. Khabilov and D.E. Tajibaeva, who defended her Ph.D.

* Corresponding author: tk.khabilov@gmail.com 
thesis in 2018 on the topic: "The current state and protection measures of populations of the Red Data Book species bats of Northern Tajikistan". In it, she presented new data on the species composition, distribution and number of bats in the territory of Northern Tajikistan and the valley of the Zeravshan River (Table 2). As a result of these studies, the species composition of bats in Tajikistan was replenished with one more species i.e. Rhinolophus lepidus Blyth, 1844, and now it has already 20 species. Bukhara bat Myotis bucharensis Kuzaykin, 1950 (former name - Myotis frater Allen, 1923), a single kind in the south of Tajikistan, in Ayvaj in 1915, was again found in 2019, 105 years later, in the valley of the Zeravshan River and thus, its existence in Central Asia was confirmed again. If we compare the data shown in table 1 collected in the period 1976-1989 and the data of table 2 collected in the period 2009-2017, then we can see the noticeable changes within these two periods.

Table 1. Composition of bats fauna of Tajikistan and its distribution [Khabilov, 2003]

\begin{tabular}{|c|c|c|c|c|c|c|c|}
\hline \multirow[t]{2}{*}{ № } & \multirow{2}{*}{ Kind } & \multicolumn{2}{|c|}{$\begin{array}{c}\text { Northern } \\
\text { Tajikistan* }\end{array}$} & \multicolumn{2}{|c|}{$\begin{array}{c}\text { South-West } \\
\text { Tajikistan } \\
\end{array}$} & \multirow{2}{*}{ Badakhshan } & \multirow{2}{*}{ Pamirs } \\
\hline & & $\begin{array}{l}\text { Mountain } \\
\text { foothills }\end{array}$ & Valley & $\begin{array}{l}\text { Mountain } \\
\text { foothills }\end{array}$ & Valley & & \\
\hline 1. & Rhinolophus hipposideros Bechst. & + & ++ & + & + & + & - \\
\hline 2. & Rhinolophus ferrumequinum Schreb. & ++ & + & + & + & - & - \\
\hline & Rhinolophus bocharicus Kaŝt. ct. Akim. & + & - & + & + & - & - \\
\hline 4. & Myotis blythii Tomes. & +++ & ++ & + & ++ & - & - \\
\hline 5. & Myotis emarginatus Geofr. & + & + & + & + & - & - \\
\hline 6. & Myotis mystacinus Kuhl. & + & + & + & + & + & - \\
\hline & Myotis frater Allen. & - & + & - & + & - & - \\
\hline 8. & Plecotus austriacus Fischer & ++ & - & + & + & + & - \\
\hline 9. & Barbastella leucomelas Gretchmar. & ++ & + & + & - & + & - \\
\hline & Miniopterus schreibersi Kuhl. & - & + & - & - & - & - \\
\hline & Nyctalus noctula Schreb. & - & + & - & - & - & - \\
\hline 12. & Pipistrellus pipistrellus Schreb. & + & +++ & - & +++ & - & - \\
\hline 13. & Pipistrellus savii Bonaparte & + & - & $+?$ & + & - & + \\
\hline 14. & Eptesicus serotinus Schreb. & + & + & + & ++ & - & - \\
\hline 15. & Eptesicus bottae Peters & - & +++ & + & + & - & - \\
\hline 16. & Eptesicus gobiensis Bobrinskoy & - & - & - & - & - & + \\
\hline 17. & Vespertilio murinus L. & + & + & - & + & - & - \\
\hline 18. & Otonycteris hemprichi Peters & + & - & $+?$ & + & + & - \\
\hline 19. & Tadarida teniotis Rafinesque & - & - & + & + & - & - \\
\hline & overal: & $13 \mathrm{k}$ & $13 \mathrm{k}$ & $11 \mathrm{k}$ & $15 \mathrm{k}$ & $5 \mathrm{k}$ & $2 \mathrm{k}$ \\
\hline & total:** & \multicolumn{2}{|c|}{$17 \mathrm{k}$} & \multicolumn{2}{|c|}{$16 \mathrm{k}$} & \multicolumn{2}{|l|}{$7 \mathrm{k}$} \\
\hline
\end{tabular}

Symbols: Estimated number: + rare or few (1-9 in one shelter); ++ common (10-99); +++ numerous (100-999); +? not found, but likely.

* including the valley of Zeravshan River

** the table includes all known places of finds of bats, both according to literature data (from 1873 to 2003) and according to the author's research on the territory of Tajikistan in the period 1976 to 2003.

It describes in detail the changes that have occurred in the species composition, numbers and distribution of bats on the territory of Tajikistan over the past 40-50 years. An analysis of bat biodiversity has been carried out, the trend of its changes has been identified and measures for the conservation of these unique animals in the future on the territory of Tajikistan have been proposed.So, the first most noticeable change immediately catching the eye is the disappearance of some large colonies of bats discovered in the $70-80^{\text {th }}$ of the last century in the Mogol-Tau mountains, Qurama and Turkestan Mountain ranges. In part, this was due to direct human intervention. This is how the Koni-Mansur cave near the village of Adrasman on the Qurama mountain range was destroyed due to mining. This was the largest cave in the territory of Northern Tajikistan, where more than 3000 Myotis blythii Tomes, 1857 lived in summer. The same happened with the abandoned adit in Uch-Bog settlement suburbs in the Mogol-Tau mountains as a result of stone extraction, where the colony of 250-300 females of this species lived there. Also, the colony of 800 Great Horseshoe Bone living in an adit of Uch-Teppa settlement suburbs in the same mountains last summer is no longer found there now 
Table 2. The modern composition of bats fauna of Tajikistan and its distribution*

\begin{tabular}{|c|c|c|c|c|c|c|c|}
\hline \multirow[t]{2}{*}{ № } & \multirow{2}{*}{ Kind } & \multicolumn{2}{|c|}{ Northern Tajikistan } & \multicolumn{2}{|c|}{$\begin{array}{l}\text { South-West } \\
\text { Tajikistan }\end{array}$} & \multirow{2}{*}{ Badakhshan } & \multirow{2}{*}{ Pamirs } \\
\hline & & $\begin{array}{l}\text { Mountain } \\
\text { foothills }\end{array}$ & Valley & $\begin{array}{l}\text { Mountain } \\
\text { foothills }\end{array}$ & Valley & & \\
\hline 1. & $\begin{array}{l}\text { Rhinolophus hipposideros } \\
\text { (Borkhausen, 1797) }\end{array}$ & + & + & + & + & + & - \\
\hline 2. & Rhinolophus lepidus Blyth & + & - & + & - & - & - \\
\hline 3. & $\begin{array}{l}\text { Rhinolophus ferrumequinum } \\
\text { Schreber }\end{array}$ & + & + & $+* *$ & $+* *$ & - & - \\
\hline 4. & $\begin{array}{l}\text { Rhinolophus bocharicus Kaŝenko et } \\
\text { Akimov }\end{array}$ & ++ & + & $+* *$ & ++ & - & - \\
\hline 5. & Myotis blythii Tomes & +++ & + & ++ & + & - & - \\
\hline 6. & Myotis emarginatus Geoffroy & - & - & + & $+* *$ & - & - \\
\hline 7. & Myotis davidii (Peters, 1869) & - & + & + & - & - & - \\
\hline 8. & Myotis bucharensis Kuzakin & - & + & - & + & - & - \\
\hline 9. & Plecotus strelkovi Spitzenberger & + & - & - & - & - & - \\
\hline 10. & Barbastella caspica Satunin & ++ & + & + & $+* * ?$ & - & - \\
\hline 11. & Miniopterus pallidus Thomas & - & - & - & - & - & - \\
\hline 12. & Nyctalus noctula Schreber & - & - & - & - & - & - \\
\hline 13. & Pipistrellus pipistrellus Schreber & ++ & +++ & $++* *$ & +++ & - & - \\
\hline 14. & Hypsugo savii Bonaparte & + & - & $+* *$ & + & - & - \\
\hline 15. & Eptesicus serotinus Schreber & + & - & $* * ?$ & $* *$ & - & - \\
\hline 16. & Eptesicus ognevi Bobrinskoy & + & - & + & + & - & - \\
\hline 17. & Eptesicus gobiensis Bobrinskoy & - & - & - & - & - & + \\
\hline 18. & Vespertilio murinus Linnaeus & - & - & - & + & - & - \\
\hline 19. & Otonycteris leucophaea, Severtsov & - & - & $* * ?$ & + & - & - \\
\hline 20. & Tadarida teniotis Rafinesque & - & - & $* *$ & $* *$ & - & - \\
\hline & overal: & $11 \mathrm{k}$ & $8 \mathrm{k}$ & $12 \mathrm{k}+2 *$ & $12 \mathrm{k}+2$ & $1 \mathrm{k}$ & $1 \mathrm{k}$ \\
\hline & Total:*** & \multicolumn{2}{|c|}{$13 \mathrm{k}$} & \multicolumn{2}{|c|}{$13 \mathrm{k}+2$} & \multicolumn{2}{|c|}{$2 \mathrm{k}$} \\
\hline
\end{tabular}

* symbols are the same as in table 1 ;

** the animals were counted using an ultrasonic detector during the hunting;

*** the table was compiled on the basis of collections of bats in the period from 2009 to 2020 .

$* * * *$ the species in bold type in the table above show those species that their number decreased during study period.

The colony of Rhinolophus ferrumequinum Shreber, 1774 and Rhinolophus bocharicus Kastshenkoet Akim, 1917, numbering about 1200-1300 found on the Qurama mountain range [17] in Altyn-topkan (Zarnisor) settlement suburbs at an altitude of $1590 \mathrm{~m}$ above sea level. But, other wintering colony consisting of about 700 bats was found in 2016 in this settlement itself (1240 $\mathrm{m}$ above sea level). Also, the fate of the multi-thousand (2000-3000 bats) colony of M. blythii having lived for many years in the natural cave on the southern slope of Turkestan Mountain ranges in Maykata is unknown, no bats were found there in August 2016, and 3 years later, in 2019, a colony of $M$. blythii was rediscovered by cavers.

Of course, the disappearance of such large bats colonies is the most worrying event in the last 45 years. However, it is important to study the changes happened in bats species composition and number at our stations (abandoned mines) in the Mogol-Tau mountains and the foothills of the northern slope of the Turkestan Mountain ranges. Two of them were chosen by us as experimental ones (in Chayruh-Dayron and Dahana settlements).

In total, there were 8 mines regularly monitored since 1976 to the present day with a break in 1995-2010.
Three of them were in the Mogol-Tau mountains, and five in the Guzlon mountains near Isfara town suburbs. A experimental mine in the Mogol-Tau mountains is in the eastern part of these mountains in Choyrukh-Dayron settlement ( $\mathrm{N} 40^{\circ} 23$, E $96^{\circ} 40$; height $590 \mathrm{~m}$ above sea level) $20 \mathrm{~km}$ north of Khujand city. The main work and observations were carried out in an abandoned mine № 4 in Dahana (N 40 11 , E 70 46 ; height $1047 \mathrm{~m}$ above sea level) in the foothills of northern slope of the Turkestan Mountain ranges, $14 \mathrm{~km}$ northeast of Isfara (Guzlon mountains).

The results of these observations showed [18] that earlier in the $70-80^{\text {th }}$ of the last century, 11 species of bats were recorded in the Mogol-Tau mountains: Rhinolophus hipposideros Borkhausen 1797, $R$. ferrumequinum, R. bocharicus, Myotis blythii, $M$. emarginatus Geoffroy 1806, Plecotus strelkovi, Spitzenberger 2006, Barbastella caspica Satunin, 1908, Pipistrellus pipistrellus, Hypsugo savii Bonaparte, Vespertilio murinus Linnaeus, 1758, Eptesicus serotinus Shreber, 1774. Only the following 5 species were caught here within the last 8 years: Rhinolophus ferrumequinum, $R$. bocharicus, Myotis blythii, M. emarginatus, Eptesicus serotinus. 
Pipistrellus pipistrellus is the most abundant species in Central Asia and Tajikistan. It previously wintered in Chairukh-Dayron settlement mine and lived in human buildings in the settlement in summer. However, it has never been found as before in this abandoned mine in winter. As well, such species as Barbastella caspica, Hypsugo savii, Vespertilio murinus previously systematically encountered here during winter, have never been found wintering here. This can hardly be considered accidental. Of course, the influence of the anthropogenic factor cannot be ruled out, since people sometimes visited the mine, using even torches, however, there are 3 circumstances against this factor:

1. In the early $2000^{\text {th }}$ entrance to the mine was filled up almost completely and there was a hole only in the upper part, approximately $1 \mathrm{~m}$ high and $2 \mathrm{~m}$ wide, which was not visible to visitors from the outside. It did not affect the microclimatic regime inside the mine, since there was a vertical well communicating with the mountain surface in the lateral passage. There was a cold draft here, both in summer and in winter, which is typical for this particular mine and attracted various species of bats for wintering, i.e. this was a typical "winter" mine.

2. Pipistrellus pipistrellus, Hypsugo savii, Vespertilio murinus, Eptesicus serotinus always hibernating in deep horizontal round boreholes after drilling and, therefore, were not visible and accessible to casual visitors during wintering and thus were not directly influenced by humans.

3. Rhinolophus ferrumequinum and R. bocharicus are very sensitive bats to human visits, usually in winter hibernating openly in the central and lateral passages of the mine, still continue wintering there now. If there had been anthropogenic influence, then just these species would have stopped hibernating in this mine first of all, but not the above mentioned petrophilic species wintering in the mine.

It is a fact that the species diversity of wintering bats in an abandoned mine in the Mogol-Tau mountains in Chayruh-Dayron settlement is decreasing. In our opinion, these changes cannot be the direct influence of the anthropogenic factor.

Another example of changes in the species composition and number of bats are the results of observations in mine № 4 in the foothills of the northern slope of the Turkestan Mountain range in Isfara suburbs near Dahana, which is a habitat for bats throughout the year. During our 54 study visits (20 times in spring, 12 times in summer, 9 times in autumn and 13 times in winter), the following 8 species of bats were found in this mine in 1976 to 1987 in all seasons of the year: Rhinolophus bocharicus, R. ferrumequinum, Myotis blythii, Plecotus strelkovi, Barbastella caspica, Pipistrellus pipistrellus, Hypsugo savii, Eptesicus serotinus. However, 25 years later (since 2012) to the present time, Pipistrellus pipistrellus and Hypsugo savii species mentioned earlier were not found in this mine in autumn and winter during 30 visits (11 times in spring, 7 times in summer, 6 times in autumn and 6 times in winter). However, Eptesicus ognevi Bobrinskiy, 1918, which had not previously been found wintering in the territory of Central Asia, was found here. The number of the most common species of bats has significantly changed in this mine over the past 45 years (Table 2). According to our data [19], compared with all 9 species found in mine № 4 Rhinolophus bocharicus, Plecotus strelkovi and Barbastella caspica species which were abundant in $70-80^{\text {th }}$ of the last century reduced their numbers in this mine by 4,6 and 2 times, respectively. At the same time, the number of Rhinolophus ferrumequinum and especially, Myotis blythii has increased that we do not know the exact reason so far. This increase of number might be to some extent due to global climate change, but it is difficult to answer why this is a negative trend for some species, while positive for others (if so). Ecological plasticity in bats of different origins, as well as their ecological norm, are different and therefore, the reaction to changes in the external environment should be manifested in different ways in representatives of different families, genera and species.

Earlier [19], we suggested that aridization of the climate through the vegetation of foothills and mountains (ephemerals and ephemeroids) can affect the food supply (insects) of bats, creating its instability in certain years and thereby, reducing reproduction of their populations. However, this assumption needs to be confirmed by meteorological data for the last 50 years in the study area, which would show climatic changes during this period and their impact on the existing biota.

The diagram 1 and 2 below show the changes of medium year size temperature and humidity during the last 45 years in North Tajikistan and we see the raise of medium temperature in this period on the rate of 1.1 degree and drop of middle norms of humidity to $0,4 \%$.

Obviously, such studies are probably already the next stage in monitoring and studying the ecology of bat populations on the territory of Northern Tajikistan and are necessary for understanding the intrapopulation structure of bats and their dynamics in time and space connected with environmental factors.

At this stage of research, we can draw several conclusions, which we think reflect the results of our field studies in 1976-2020 and show the change in the species composition and number of bats in the MogolTau mountains and the foothills of the northern slope of the Turkestan Mountain ranges in the territory of Northern Tajikistan:

1. We believe that our studies of bats on the territory of Northern Tajikistan in 1976-2020 are very important, since for the first time in Tajikistan and Central Asia, a comparison and analysis of changes in the species composition, distribution and number of bats was carried out.

2. These studies have shown a large-scale reduction in the species composition of hibernating bats, from 11 to 5 species, in the Mogol-Tau mountains, and from 8 to 6 species of bats in the foothills of the northern slope of the Turkestan Mountain ranges. During the same period, the number of Rhinolophus bocharicus, Plecotus strelkovi and Barbastella caspica decreased by 4, 6 and 2 times in mine № 4. But the number of Rhinolophus 
ferrumequinum, specifially Myotis blythii, has increased several times. Also, a new hibernating species Eptesicus ognevi were found which had not previously been found wintering in Tajikistan and Central Asia.

3. In our opinion, these changes are not only due to the direct anthropogenic influence of man on the habitats (mines) of bats, although the Koni Mansur cave and the mine in Uch-bogh settlements, where the summer colonies of Myotis blythii lived in the territory of Northern Tajikistan, were ruined as a result of direct human intervention (mining). It is assumed that these changes of species diversity and number of bats are associated with global climate change, but still it just an assumption and requires further careful study and approval by instrumental methods connecting with other environmental factors.

In the future, when carrying out similar studies, it is useful to supplement such studies with the capture of bats near their habitats with mist net, as well as the identification of their species and number using an ultrasonic detector in addition to studying bats' caves and mines.

\section{Acknowledgments}

The authors express their sincere thankfulness to the resident of Isfara city Dadokhonov Kurbon for his impartial assistance at all stages of field study.

\section{References}

1. T.K. Khabilov, The Fauna of the Republic Tajikistan. Mammals. Bats. Volume XX, part 7 (1992)

2. T.K. Khabilov, The Fauna of the Republic Tajikistan. Mammals. Bats. Volume XX, part 8 (2003)

3. D.E. Tadzhibaeva, Candidate of science $(\mathrm{PhD})$ dissertation. (2018)

4. N.A. Severtsov, Bulletin of lovers of natural science, anthropology and ethnography 8(2), 157 (1873).

5. O.P. Bogdanov, Bulletin of Academy of Sciences of the Uzbek Republic 4, 129-130 (1950)

6. O.P. Bogdanov, Bulletin of Academy of Sciences of the Uzbek Republic 2, 95-96 (1952)

7. O.P. Bogdanov, Report of Academy of Sciences of Tajik Republic 13, 17-19 (1954)

8. O.P. Bogdanov, Zoology Journ. 35(7), 1097-1099 (1956a)

9. O. P. Bogdanov, Report of Academy of Sciences of Tajik Republic 15, 69-75 (1956b).

10. T.K. Khabilov, Abstracts of Republican conference of young scientists, 149-150 (1977)

11. T.K. Khabilov, Abstracts of Republican conference of young scientists dedicated to $110^{\text {th }}$ anniversary of the birth of V.I. Lenin, 94-96 (1980)

12. T. K. Khabilov, Biological aspects of the protection of rare animals, 113-115 (1981).
13. T.K. Khabilov, Author's abstract of doctorate (Candidate of science) of biology dissertation (1983)

14. T.K. Khabilov, Report of Academy of Sciences of Tajik Republic 29(10), 628-631 (1986)

15. T.K. Khabilov, Proceedings of all-union seminar (Kiev, 1988)

16. T.K. Khabilov, O.P. Bogdanov, Scientific notes of Khujand State University named after academician B. Gafurov 3, 126-136 (2001)

17. T.K. Khabilov, Report of Academy of Sciences of Tajik Republic 1, 89-92 (1979)

18. D.E. Tajibaeva, T.K. Khabilov, Plecotus et al. 22, 8087 (2019)

19. T.K. Khabilov, D.E. Tajibaeva, Plecotus et al. 23, 31$49(2020)$ 